\title{
Calibration of ultrasonic power output in water, ethanol and sodium polytungstate
}

\author{
Axel Mentler ${ }^{1 *}$, Jasmin Schomakers ${ }^{1}$, Stefanie Kloss ${ }^{1}$, Sophie Zechmeister-Boltenstern ${ }^{1}$, \\ Reinhard Schuller ${ }^{2}$, and Herwig Mayer ${ }^{2}$ \\ ${ }^{1}$ Department of Forest and Soil Sciences, Institute of Soil Research, \\ ${ }^{2}$ Department of Material Sciences and Process Engineering, Institute of Physics and Material Sciences; \\ University of Natural Resources and Life Sciences, Peter-Jordan 81, 1190 Vienna, Austria
}

Received July 4, 2017; accepted October 9, 2017

\begin{abstract}
Ultrasonic power is the main variable that forms the basis for many soil disaggregation experiments. Thus, a procedure for the rapid determination of this variable has been developed and is described in this article. Calorimetric experiments serve to measure specific heat capacity and ultrasonic power. Ultrasonic power is determined experimentally for deionised water, $30 \%$ ethanol and sodium polytungstate with a density of $1.6 \mathrm{~g} \mathrm{~cm}^{-3}$ and $1.8 \mathrm{~g} \mathrm{~cm}^{-3}$. All experiments are performed with a pre-selected ultrasonic probe vibration amplitude. Under these conditions, it was found that the emitted ultrasonic power was comparable in the four fluids. It is suggested, however, to perform calibration experiments prior to dispersion experiments, since the used fluid, as well as the employed ultrasonic equipment, may influence the power output.
\end{abstract}

Keyw ord s: ultrasonic power calibration, ultrasonic soil disaggregation, specific heat capacity measurements, sodium polytungstate, sodium polytungstate

\section{INTRODUCTION}

Ultrasonic disaggregation of soil is a widely used method for breaking down soil aggregates. The aggregates are dispersed in a fluid (typically water) in which a vibrating ultrasonic probe emits acoustic pressure waves. Disaggregation is based on a purely physical process subjecting the soil aggregates to mechanical forces that rupture the organic bonds between sub-aggregates and particles. No chemical substances are necessary, which simplifies further chemical analysis of the obtained compounds. Ultrasonic dispersion using high energies per unit volume can be used for a complete disaggregation of soil particles for further measurement of particle size distribution. Ultrasonic experiments using low ultrasonic energies in combination

*Corresponding author e-mail: axel.mentler@boku.ac.at with sieving can be used to quantify soil aggregate stability. Stability assessment is based on the notion that the lower energy needed for disaggregating soil samples into smaller compounds and particles, the lower the stability of the soil. The used ultrasonic energies per unit volume of soil suspension for partial or total aggregate disruption vary widely in a range from 7 to $5350 \mathrm{~J} \mathrm{ml}^{-1}$ (Cerli et al., 2012; Christensen, 1992; Schomakers et al., 2011).

Ultrasonic dispersion for aggregate disruption is also a step often applied during soil density fractionation. Sonication releases the light fraction occluded in aggregates. This represents an important soil organic matter (SOM) fraction (Golchin et al., 1994). Within the past years, SOM research has increasingly focused on analysing different SOM fractions rather than bulk soil (Cusack et al., 2011; Larionova et al., 2015; Lehtinen et al., 2015; Wiesmeier et al., 2014). The objective of soil fractionation is to isolate functional SOM pools that differ in SOM turnover time, quality and specific carbon stabilisation mechanisms (Sollins et al., 1996; von Lützow et al., 2007). Depending on the fractionation method, SOM can be separated into three to five functional pools. These pools include one or two labile/active pools, two to three intermediate/slow pools (physically/chemically protected), and a passive/inert pool (Christensen, 1996; Zimmermann et al., 2007). As opposed to harsh chemical fractionation methods, physical methods such as particle size and density fractionation are increasingly applied - because they are considered to be less destructive (Morra et al., 1991; von Lützow et al., 2007). Density fractionation is based on the separation of the light fraction (mainly consisting of young,

(C) 2017 Institute of Agrophysics, Polish Academy of Sciences 
fresh plant residues) and the mineral-associated heavy fraction, using high density fluids. Soil scientists currently focus on using sodium polytungstate $\left(\mathrm{SPT}, \mathrm{Na}_{6}\left(\mathrm{H}_{2} \mathrm{~W}_{12} \mathrm{O}_{40}\right)\right.$ ) as a density agent rather than organic fluids, because it is less toxic than previously used fluids and the density can be adjusted to any range between 1.0 and $3.1 \mathrm{~g} \mathrm{~cm}^{-3}$ (Six et al., 1999).

The main parameter in an ultrasonic disaggregation experiment is the applied ultrasonic energy per unit volume of soil suspension $\left(E V^{-1}\right)$. This specific energy can be calculated with the ultrasonic power $\left(P_{U S}\right)$ of the equipment, the volume of the fluid where aggregates are inserted $(V)$, and the duration of the sonication experiment $(t)$, according to Eq. (1).

$$
E V^{-1}=\frac{P_{U S} t}{V} .
$$

It is necessary to exactly know the ultrasonic power emitted into the soil suspension so as to calibrate the ultrasonic dispersion experiment. The ultrasonic power is determined by the particular equipment, by the parameters adjusted at the equipment and by the experimental setup. Additionally, the ultrasonic power can be influenced by the kind of fluid used to disperse the soil aggregates.

Ultrasonic experiments are frequently performed in water, and calorimetric methods are employed to calibrate the ultrasonic power. North (1976) suggested measuring the temperature increase $(\Delta T)$ of water during a specific sonication time $(\Delta t)$, and calculating the ultrasonic power $\left(P_{U S}\right)$ in accordance with Eq. (2).

$$
P_{U S}=\left(m_{W} c_{W}+m_{v} c_{v}\right) \frac{\Delta T}{\Delta t}+H .
$$

The mass of water $\left(m_{W}\right)$ and its specific heat capacity $\left(c_{W}\right)$, the mass of the vessel $\left(m_{V}\right)$ and its specific heat capacity $\left(c_{v}\right)$, as well as the heat loss to the environment $(H)$, is considered in this equation.
An adapted method especially appropriate to determine ultrasonic power at low vibration amplitudes close to the cavitation limit was developed in the authors' laboratory (Schomakers et al., 2011). This method of calibrating ultrasonic dispersion experiments is applied in the present investigation.

In the present study, we calibrated the ultrasonic power in different fluids, by measuring the power at a well-defined ultrasonic probe vibration amplitude in four different fluids: Water (which is most widely used for ultrasonic disaggregation experiments); water-ethanol solution; SPT (with two different densities that are in common use in ultrasonic experiments). Calibration requires the exact knowledge of the specific heat capacity of the used fluids. The specific heat capacity is known from the literature for water and water-ethanol solution. The specific heat capacity of SPT, however, is not available from the literature and therefore had to be measured.

\section{MATERIALS AND METHODS}

The specific heat of the fluids was determined by heating a certain mass of the fluid with a defined thermal energy. Measurements were performed with water, $30 \%$ ethanol and two SPT fluids. The fluids are SPT 1.6 (SPT1, Tungsten, Grub am Forst, Germany) - with a nominal density of $1.6 \mathrm{~g} \mathrm{~cm}^{-3}$, and SPT 1.8 with a nominal density of $1.8 \mathrm{~g} \mathrm{~cm}^{-3}$. The densities of both SPT fluids were controlled with a pycnometer. These measurements revealed actual densities of 1.607 and $1.827 \mathrm{~g} \mathrm{~cm}^{-3}$, respectively.

The experimental setup is shown in Fig. 1. Electric current flowing through a resistor over a certain time period provides heating, which, in turn, generates an increase of temperature of a known mass of fluid. In detail, $250 \mathrm{~g}$ of fluid was given into a $500 \mathrm{ml}$ closed polystyrene vessel that was insulated with styrofoam and air cushion foil. To ensure an even temperature distribution in the
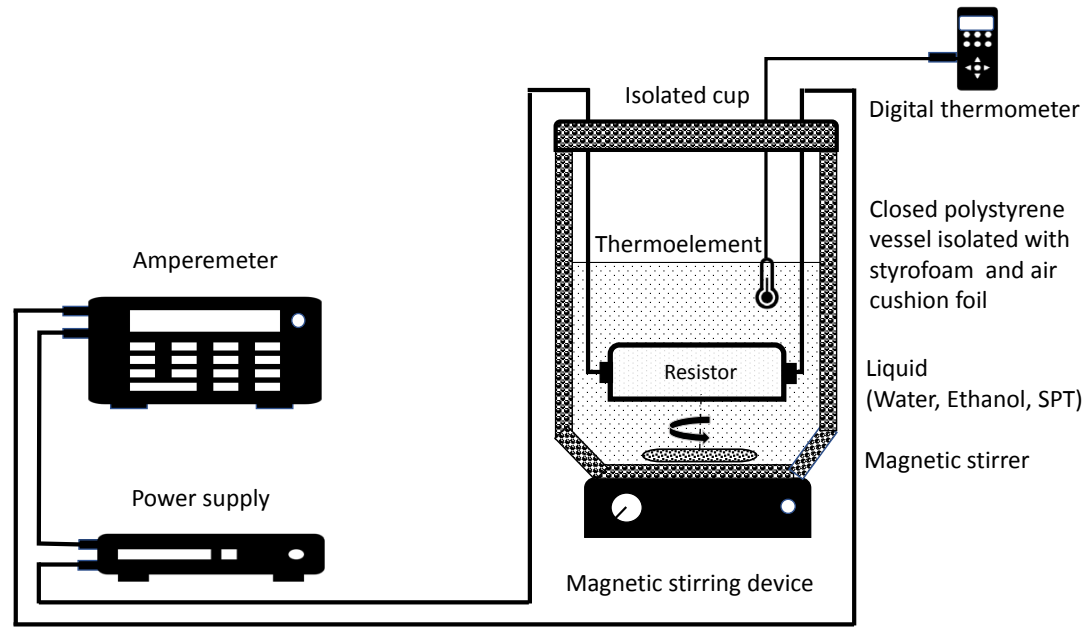

Fig. 1. Experimental setup used to measure the specific heat capacity of different fluids. The supplied power delivers constant direct current, which is controlled with an ampere meter and flows through a high precision resistor. The temperature of the fluid is measured with a $\mathrm{K}$ type thermosensor with drag indicator. A thermo-insulated vessel is used as a container. 
fluid, the vessel was equipped with a magnetic stirrer and placed upon a stirring unit, on which a silicone pad was positioned so as to isolate the vessel from the bottom. The exact temperature was determined using a Voltcraft K202 Data Logger Thermometer (K type, precision better than \pm $0.1^{\circ} \mathrm{C}$ ) with 2 thermosensors. Energy transfer into the solution was provided by a water-proof high precision resistor (SRS components) with a resistivity of $\mathrm{R}=6.77 \Omega$ that was connected to a TE Electronic KA 3500D DC Power supply. In addition, an Agilent 34410A Digital Multimeter was mounted to the resistor to test the electrical current.

The heat produced by the resistor, $(\Delta Q)$ during the time period $(\Delta t)$ is determined by its resistance $(R)$ and the electrical current (I), according to Eq. (3):

$$
\Delta Q=R I^{2} \Delta t
$$

A direct current of $I=3$ A was used.

The heat produced by the resistor leads to an increase of temperature of the fluid $(\Delta T)$. Additionally, heat exchanged with the environment $\left(\Delta Q_{E X}\right)$ must be considered. This leads to Eq. (4):

$$
\Delta Q+\Delta Q_{E X}=\left(m_{F} c_{F}+m_{R} c_{R}\right) \Delta T .
$$

The mass of the fluid $\left(m_{F}\right)$ and its specific heat capacity $\left(c_{F}\right)$, and the mass of the resistor $\left(m_{R}\right)$ and its specific heat capacity $\left(c_{R}\right)$ must be considered. The mass of the resistor is $17 \mathrm{~g}$, with a case made of aluminium, with a specific heat capacity of $0.90 \mathrm{~kJ} \mathrm{~kg}^{-1} \mathrm{~K}^{-1}$. The influence of the vessel on the measurement is estimated to be far below $1 \%$ due to its comparably low mass, and is therefore ignored.

$\Delta Q_{E X}$ is a positive number if the temperature of the environment is higher than the temperature of the fluid, and it is negative if the temperature is lower. To cancel out the contribution of $\Delta Q_{E X}$, the experiments were started with the temperature of the fluid below room temperature, and the experiments ended when the temperature of the fluid was higher than room temperature by the same amount. The presented experiments were started with fluid temperature of about $15^{\circ} \mathrm{C}$ and ended when the temperature was about 25 , with $20^{\circ} \mathrm{C}$ being the room temperature. Using this procedure, $\Delta Q_{E X}=0$ can be employed.

With Eqs (3) and (4), the specific heat capacity of the fluid can be determined with Eq. (5):

$$
c_{F}=\frac{R I^{2}-m_{R} c_{R} \frac{\Delta T}{\Delta t}}{m_{F} \frac{\Delta T}{\Delta t}} .
$$

The ultrasonic power was determined under welldefined and closely similar conditions in all the investigated fluids. The vibration amplitude of the ultrasonic probe was in the range between 24.4 and $24.7 \mu \mathrm{m}$. The displayed power on ultrasonic equipment may be significantly different from the actual power, and is therefore unreliable (Schmidt et al., 1999). Thus, the ultrasonic power was determined for a certain vibration amplitude and not for a certain displayed power. The method to measure ultrasonic vibration amplitudes is described elsewhere (Mayer et al., 2002).

The measurements of ultrasonic power were performed with a widely used probe-type ultrasonic equipment (Bandelin Sonopuls HD 2200, cylindrical ultrasonic probe with a diameter $\varnothing 13.7 \mathrm{~mm}$ ). Tests were run in a continuous mode (non-pulse mode). The ultrasonic probe was inserted into the fluid to an insertion depth of $10 \mathrm{~mm}$.

The first series of experiments was performed with water. The ultrasonic power $\left(P_{U S}\right)$ is determined by Eq. (6) (Schomakers et al., 2011):

$$
P_{U S}=m_{W} c_{W} \frac{\Delta T}{\Delta t}-\frac{\Delta Q_{E X}}{\Delta t} .
$$

$P_{U S}$ is assessed by sonicating the fluid, where $m_{W}$ is the mass of the fluid and $c_{W}$ is its specific heat capacity. The increase of temperature $\Delta T$ in a given time period $\Delta t$ is measured. In the present tests, $150 \mathrm{~g}$ of water were poured into a $250 \mathrm{ml}$ polystyrene beaker, isolated with a silicon pad from the bottom. The solution was sonicated, and the temperature was noted every $30 \mathrm{~s}$.

The heat exchanged with the environment, $\Delta Q_{E X}$ must be considered. $\Delta Q_{E X}$ is a positive number if the temperature of the environment is higher than the temperature of the fluid, and it is negative if the temperature is lower. To cancel out the contribution of $\Delta Q_{E X}$, the experiments were started with the water temperature below room temperature. The experiments ended when the temperature of the fluid was higher than room temperature by the same amount. Using this procedure, $\Delta Q_{E X}=0$ in Eq. (6) and leads to the simpler Eq. (7).

$$
P_{U S}=m_{W} c_{W} \frac{\Delta T}{\Delta t}
$$

\section{RESULTS}

The specific heat capacity of deionised water was determined in the first series of experiments. In one, the temperature of $m_{F}=0.25 \mathrm{~kg}$ water increased by $\Delta T=8.6 \mathrm{~K}$ after it was heated by $I=3$ A flowing through a resistor of $R=6.77 \Omega$ for $\Delta t=150 \mathrm{~s}$. With the mass $m_{R}=0.017 \mathrm{~kg}$ and the specific heat capacity of the resistor, $c_{R}=900 \mathrm{~J} \mathrm{~kg}^{-1} \mathrm{~K}^{-1}$, Eq. (5) delivers the specific heat capacity of $c_{F}=4050 \mathrm{~J} \mathrm{~kg}^{-1}$ $\mathrm{K}^{-1}$ for water.

The measurements were repeated 5 times. On average, the specific heat capacity of water was $4.1 \pm 0.2 \mathrm{~kJ} \mathrm{~kg}^{-1} \mathrm{~K}^{-1}$. The literature value for water $\left(4.18 \mathrm{~kJ} \mathrm{~kg}^{-1} \mathrm{~K}^{-1}\right)$ is, therefore, reasonably well reproduced in the present experiments. The specific heat capacity of $30 \%$ ethanol was determined in the experiments as $3.6 \pm 0.2 \mathrm{~kJ} \mathrm{~kg}^{-1} \mathrm{~K}^{-1}$, which is in the range of the expected value of $3.65 \mathrm{~kJ} \mathrm{~kg}^{-1} \mathrm{~K}^{-1}$ according to the 


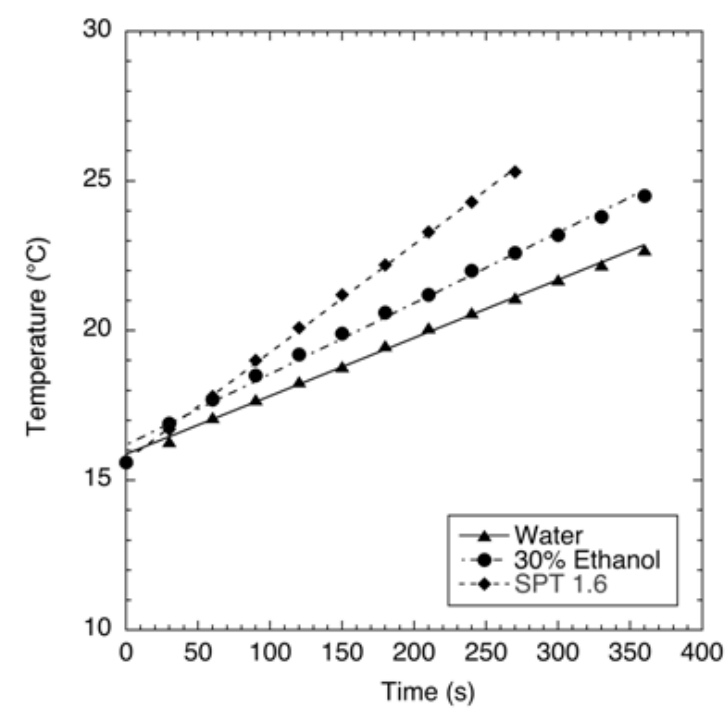

Fig. 2. Temperature measured via ultrasonic experiments with three fluids.

literature. Our study also delivered the specific heat capacity of the two SPT fluids as $2.5 \pm 0.2 \mathrm{~kJ} \mathrm{~kg}^{-1} \mathrm{~K}^{-1}$ for SPT1.6 and $2.2 \pm 0.2 \mathrm{~kJ} \mathrm{~kg}^{-1} \mathrm{~K}^{-1}$ for SPT1.8.

The ultrasonic power emitted into deionised water was determined in the first measurement series. The water temperature at the beginning was $15^{\circ} \mathrm{C}$. After sonication was initiated, the temperature was recorded every $30 \mathrm{~s}$. The experiment ended when the water temperature reached about $25^{\circ} \mathrm{C}$. Similar experiments were performed with $30 \%$ ethanol and with the two SPT fluids.

Typical results obtained in these measurements are shown in Fig. 2. The temperature is shown on the ordinate as a function of the sonication duration. Data were fitted using a linear function. The results were a temperature increase per second of $=0.0194 \mathrm{~K} \mathrm{~s}^{-1}$ for deionised water, and $=0.0236 \mathrm{~K} \mathrm{~s}^{-1}$ for water-ethanol solution, as well as $=0.0361 \mathrm{~K} \mathrm{~s}^{-1}$ for SPT1.6. The fastest temperature increase among the three fluids is found for SPT1.6, and the slowest increase is that for deionised water. This does not mean, however, that the absorbed ultrasonic power is different in the three fluids, because the specific heat capacity of the three fluids is also different.

The ultrasonic power is determined according to Eq. (7). With the used masses (about $250 \mathrm{~g}$ ) and the specific heat capacities of the respective fluids, the measured power in the three experiments shown in Fig. (2) were $20.3 \mathrm{~W}$ for water, $21.6 \mathrm{~W}$ for $30 \%$ ethanol and $22.6 \mathrm{~W}$ for SPT1.6. Measurements of the ultrasonic power were repeated 3 times for each fluid.

The following ultrasonic power was determined for vibration amplitude between 24.4 and $24.7 \mu \mathrm{m}$ for a vibrating probe with $ø 13.7 \mathrm{~mm}$ and an insertion depth of $10 \mathrm{~mm}$ :

$P_{U S}=19.6 \pm 1.5 \mathrm{~W}$ for deionised water,

$P_{U S}=21.6 \pm 1.6 \mathrm{~W}$ for $30 \%$ ethanol,
$P_{U S}=21.6 \pm 1.8 \mathrm{~W}$ for SPT1.6,

$P_{U S}=20.8 \pm 1.5 \mathrm{~W}$ for SPT1.8.

The mean value of the ultrasonic power emitted into the four fluids is comparable.

\section{DISCUSSION}

Ultrasonic soil disaggregation experiments are a wellestablished means of characterising the stability and composition of soil aggregates and fractions. Recently, ultrasonic experiments have been performed using fluids of different compositions and densities, as this enables density fractionation of soil aggregates.

Crow et al. (2015) employed densities between 1.6 and $2.6 \mathrm{~g} \mathrm{~cm}^{-3}$ for physical carbon sequestration experiments, while Grüneberg et al. (2013) performed experiments in fluid with a density $1.6 \mathrm{~g} \mathrm{~cm}^{-3}$ and different ultrasonic energies to break macro- and micro-aggregates. To embody the conceptual carbon pools, experimental techniques have been developed based on measurable carbon pools by either chemical or physical fractionation approaches (Zimmermann et al., 2007). Toriyama et al. (2015) applied a SPT solution to determine the carbon pool in sediment fraction. The results of Wang et al. (2015) show that the sequential ultrasonic extraction method is reliable with regard to the mass balance. In their study, they used different fluids for extracting the different pools (deionised water, artificial root exudates, Methanol- $\mathrm{NaOH}$, dichloromethane, n-hexane, and their mixture with acetone to extract PAHs from soils).

Knowledge of the applied ultrasonic power is a necessity for well defined ultrasonic experiments. The above results show that the absorbed ultrasonic power is comparable in four different fluids under the investigated conditions and using the described ultrasonic equipment. It should be noted that the increase of temperature during sonication is different for the four fluids. However, if the specific heat of the respective fluid is considered, the ultrasonic power determined in the four testing series did not show much difference. The condition of constant vibration amplitude was, thus, found to be closely similar to the condition of constant ultrasonic power - if other geometrical conditions (diameter of the ultrasonic probe, insertion depth), as well as the surface condition of the probe were kept constant.

From a practical point of view, the applied Bandelin ultrasonic system was found to be appropriate for the present tests. When the same power setting is adjusted at the instrument (i.e. $10 \%$ of the maximum power in the present experiments), the vibration amplitude was found to be closely similar irrespective of the investigated fluid. No further adjustment or considerations of the used fluids were necessary. This poses the question whether the absorbed ultrasonic power for the same setup conditions is always the same, irrespective of the used fluid. 
It must be assumed that the presently found result is, first at all, specific for the study's experimental conditions, i.e. measurements with constant vibration amplitude and geometrical conditions. It has been shown that commercial instruments may show large variations when compared with each other. Additionally, their ultrasonic power may vary from the displayed power by $100 \%$ or more (Schmidt et al., 1999). Even employing identical ultrasound equipment several times may lead to different calibrations. Experiments performed with one type of ultrasonic device, therefore, may be completely incomparable to those performed with other devices.

Additionally, the fluid used in the sonication experiment might influence the absorbed power. For constant vibration amplitude, the acoustic pressure in different fluids varies due to their different acoustic impedance. In commercial ultrasonic equipment, the acoustic pressures are above the cavitation limit, and cavitation will hence occur. The cavitation limit, however, is influenced by the physical properties of the fluid. Therefore, the used fluid might influence the absorbed ultrasonic power.

Due to both reasons, the possible influence of the ultrasonic system, as well as the possible influences of the fluid, it cannot be generally assumed that the absorbed ultrasonic power is constant irrespective of the used fluid. Rather, the comparable ultrasonic power found in the four experimental series must be considered specific for the used ultrasonic system and the investigated fluids.

\section{CONCLUSIONS}

Ultrasonic experiments on fluids with different densities are employed in the studies of soil aggregates. These experiments require the exact knowledge of the applied ultrasonic power in the respective fluid. Specific heat capacity of the applied fluid is necessary to calibrate the ultrasonic experiment.

1. A rapid method for the determination of the specific heat capacity of fluids is described. The specific heat capacity for sodium polytungstate with a density of $1.6 \mathrm{~g} \mathrm{~cm}^{-3}$ (SPT1.6) was $2.5 \pm 0.2$ and $2.2 \pm 0.2 \mathrm{~kJ} \mathrm{~kg}^{-1} \mathrm{~K}^{-1}$ was found for a SPT with a density of $1.8 \mathrm{~g} \mathrm{~cm}^{-3}$ (SPT1.8).

2. The absorbed ultrasonic power $\mathrm{P}_{\mathrm{US}}$ was determined for deionised water, 30\% ethanol, SPT1.6 and SPT1.8. When the vibration amplitude was the same in all four fluids, the ultrasonic power emitted into the fluids was comparable.

3. It is suggested to calibrate ultrasonic equipment for each fluid separately. A method for the calibration of ultrasonic power is proposed.

Conflict of interest: The Authors do not declare conflict of interest.

\section{REFERENCES}

Cerli C., Celi L., Kalbitz K., Guggenberger G., and Kaiser K., 2012. Separation of light and heavy organic matter fractions in soil- Testing for proper density cut-off and dispersion level. Geoderma, 170, 403-416.

Christensen B.T., 1992. Physical fractionation of soil and organic matter in primary particle size and density separates. Advances in Agronomy, 20, 1-90.

Christensen B.T., 1996. Matching measurable soil organic matter fractions with conceptual pools in simulation models of carbon turnover. In: Evaluation of Soil Organic Matter Models Using Long-Term Datasets (Eds D.S. Powlson, P. Smith, J.U. Smith), NATO ASI Series 1: Global Environmental Change, Springer-Verlag, Heidelberg, 38, 143-159.

Crow S.E., Reeves M., Schubert O.S., and Sierra C.A., 2015. Optimization of method to quantify soil organic matter dynamics and carbon sequestration potential in volcanic ash soils. Biogeochemistry, 123: 27-47.

Cusack D.F., Silver W.L., Torn M.S., and McDowell W.H., 2011. Effects of nitrogen additions on above- and belowground carbon dynamics in two tropical forests. Biogeochemistry, 104, 203-225.

Golchin A., Oades J.M., Skjemstad J.O., and Clarke P., 1994. Study of free and occluded particulate organic matter in soils by solid state 13C CP/MAS NMR Spectroscopy and Scanning Electron Microscopy. Soil Biol. Biochem., 32, 285-309.

Grüneberg E., Schöning I., Hessenmöller D., and Schulze E.-D., Weisser W.W., 2013. Organic layer and clay content control soil organic carbon stocks in density fractions of differently managed German beech forests. Forest Ecol. Manag., 303, 1-10.

Larionova A.A., Zolotareva B.N., Kvitkina A.K., Evdokimov I.V., Bykhovets S.S., Stulin A.F., Kuzyakov Ya.V., and Kudeyarov V.N., 2015. Assessing the stability of soil organic matter by fractionation and $13 \mathrm{C}$ isotope techniques. Eurasian Soil Sci., 48, 157-168.

Lehtinen T., Gísladóttir G., Lair G.J., van Leeuwen J.P., Blum W.E.H., Bloem J., Steffens M., and Ragnarsdóttir K.V., 2015. Aggregation and organic matter in subarctic Andosols under different grassland management. Acta Agriculturae Scandinavica, Section B-Soil and Plant Sci., 65, 246-263.

Mayer H., Mentler A., Papakyriacou M., Rampazzo N., Marxer Y., and Blum W.E.H., 2002. Influence of vibration amplitude on the ultrasonic dispersion of soils. Int. Agrophysics, 16, 53-60.

Morra M.J., Blank R.R., Freeborn L.L., and Shafii B., 1991. Size fractionation of soil organo-mineral complexes using ultrasonic dispersion. Soil Sci., 154, 294-303.

North P.F., 1976. Towards an absolute measurement of soil structural stability using ultrasound. J. Soil Sci., 27, 451-459.

Schmidt M.W.I., Rumpel C., and Kögel-Knabner I., 1999. Evaluation of an ultrasonic dispersion procedure to isolate primary organomineral complexes from soils. Europ. J. Soil Sci., 50, 87-94.

Schomakers J., Mentler A., and Mayer H., 2014. Determination of dissolved organic carbon in soils with UV spectroscopy, ultrasonic dispersion pre-treatment and separation with size exclusion chromatography. Span. J. Soil Sci., 4, 127-142. 
Schomakers J., Mentler A., Steurer T., Klik A., and Mayer H., 2011. Characterization of soil aggregate stability using low intensity ultrasonic vibrations. Int. Agrophys., 25, 165-172.

Six J., Schultz P.A., Jastrow J.D., and Merckx R., 1999. Recycling of sodium polytungstate used in soil organic matter studies. Soil Biol. Biochem., 31, 1193-1196.

Sollins P., Homann P., and Caldwell B.A., 1996. Stabilization and destabilization of soil organic matter: mechanisms and controls. Geoderma, 74, 65-105.

Toriyama J., Hak M., Imaya A., Hirai K., and Kiyono Y., 2015. Effects of forest type and environmental factors on the soil organic carbon pool and its density fractions in a seasonally dry tropical forest. Forest Ecol. Manag., 335, 147-155.

Lützow M. von M., Kögel-Knabner I., Ekschmitt K., Flessa H., Guggenberger G., Matzner E., and Marschner B.,
2007. SOM fractionation methods: Relevance to functional pools and to stabilization mechanisms. Soil Biol. Biochem., 39, 2183-2207.

Wang C., Zhu L., and Zhang C., 2015. A new speciation scheme of soil polycyclic aromatic hydrocarbons for risk assessment. J. Soils Sediments, 15, 1139-1149.

Wiesmeier M., Schad P., Von Lützow M., Poeplau C., Spörlein P., Geuß U., Hangen E., Reisch A., Schilling B., and Kögel-Knabner I., 2014. Quantification of functional soil organic carbon pools for major soil units and land uses in southeast Germany (Bavaria). Agric. Ecosyst. Environ., 185, 208-220.

Zimmermann M., Leifeld J., Schmidt M.W.I., Smith P., and Fuher J., 2007. Measured soil organic matter fractions can be related to pools in the RothC model. Europ. J. Soil Sci., 58, 658-667. 